\title{
Deferred Action: Theoretical model of process architecture design for emergent business processes
}

\author{
Nandish V. Patel \\ Brunel Organization and Systems Design Centre [BOSdc] \\ Brunel Business School, Brunel University, UB8 3PH, UK \\ Tel: +44(0) 1895265295 \\ Fax: +44 (0) 1895269775 \\ Email: nandish.patel@brunel.ac.uk
}

\begin{abstract}
E-Business modelling and ebusiness systems development assumes fixed company resources, structures, and busines s processes. Empirical and theoretical evidence suggests that company resources and structures are emergent rather than fixed. Planning business activity in emergent contexts requires flexible ebusiness models based on better management theories and models. This paper builds and proposes a theoretical model of ebusiness systems capable of catering for emergent factors that affect business processes. Drawing on development of theories of the 'action and design'class the Theory of Deferred Action is invoked as the base theory for the theoretical model. A theoretical model of flexible process architecture is presented by identifying its core components and their relationships, and then illustrated with exemplar flexible process architectures capable of responding to emergent factors.

Managerial implications of the model are considered and the model's generic applicability is discussed.
\end{abstract}

Keywords: service science, Theory of Deferred Action, theoretical model, business process, process architecture, emergence 


\section{INTRODUCTION}

The term process architecture describes artefactual objects resulting from designing and implementing business processes and the supporting IT systems. This is planned architecture. Process architecture and business organization should be in reciprocal relation to each other to improve business performance. The reciprocity is between organization and its IT systems. Research into process architecture has focused on practical aspects resulting in a body of literature on business process modelling (Miers D 1994; Elizinga D, Horak T et al. 1995; Georgakopoulos D, M et al. 1995; Reijswoud V, Mulder H et al. 1999). Less research is evident on building models based on theory, see for example Shaw et al. (2006) The question considered theoretically in this paper is how business process designers can model changing processes involving uncertainties, unpredictable futures, and non-standardisable business processes. This type of business process is termed emergent business processes (EBP) and it is not amenable to planned architecture design.

A search of leading business and management journals revealed that there is little research into the theory of process design. The journals consulted were Harvard Business Review, Academy of Management Journal and Academy of Management Review for the period 1999-2006. Slack (2005) proposes a model and Larger and Horte (2005) a taxonomy indicative of emerging theoretical perspective on process architecture design. This is in contrast to editorial support for theoretical work in management in general (Kilduff M 2007).

Editors of leading management journals and information systems journals value theory building and theory publishing (Weber R 2003). Researchers in information systems have proposed theoretical models to explain IT systems design for organizational knowledge management (Markus M L, Majchrzak A et al. 2002) and executive information systems (Walls J G, R et al. 1992). In business and management, there is little similar theory proposed for process architecture design. Shaw et al., (2007) propose a theory-based process architecture capable of evolving with business process change. They state that: 'there is no theoretical basis for any assembly of business process model constructs that we have seen.' (p.95). Kettinger and Grover (1995) propose a theory of business process management. A theoretical model of process architecture design is proposed in this paper to improve theoretical process knowledge and to address the general gap in theory building for process architecture design. The theoretical basis of process architecture design in general is weak.

Theoretical understanding provides a sound basis for designing process architecture. The central question addressed here concerns the kind of process architecture design required for emergent business processes. A theoretical understanding of process architecture design should enable appropriate responses to emergent organization - its processes and the associated process information and process knowledge. This paper addresses three related problems in process architecture design: emergent organization, planned business change, and emergent business processes (also termed nonstandardisable processes). The crucial interrelationship among these problems is not addressed in the research literature.

Theoretical models can draw on two types of theory: variance theory or process theory (Soh C and Markus M L 1995). Variance theories explain the variations in the magnitude of a certain outcome and are better at explaining 'why' something happens. Variance theories are also called linear models because of the use of linear equations to model phenomena. Variance theories do not explain well situations where the outcome is uncertain - sometimes occurring, sometimes not. Such situations indicate that the necessary conditions are not sufficient to produce the outcome. Process theories better explain situations where the causal agent is not sufficient to produce the outcome. Process theories explain 'how' something happens. They are better suited to explain process architecture design for emergent organization, as the outcome is uncertain in emergent organization and the causal agent alone is insufficient to produce the outcome.

Drawing on process theory, this paper presents a theoretical model of process architecture design for emergent business processes and emergent organization in general. Its focus is on emergent business processes. It explains process architecture design and suggests design strategies for process architecture in emergent organisation. The theoretical model is based on the postulate of emergent organization, which is evidenced in the next section. Definition of business process in the context of emergent organization is then discussed. These preliminaries aside, the theoretical framework for the theoretical model is outlined in the following two sections. First, the Theory of Deferred Action, a process theory of action and design, is outlined as the base theory for developing the theoretical model. Then the 'non-trivial machine' cybernetic concept and the active model modelling concept are presented. The theoretical model draws on these concepts to improve EBP design. This sets the background for elaborating the theoretical model of process architecture design for EBP. The theoretical model is illustrated in the penultimate section with exemplar process-oriented IT systems. 
The concluding section is a summary and description of further ongoing theoretical and design research in process architecture design.

\section{EMERGENT ORGANISATION}

A business model and its internal logic can be specified to form the basis for process architecture design. Many entities composing business processes can be predicted. In a supply chain the supplier, materials, quantities, locations, and times when required can be predicted. In the main, business rules, organizational processes, procedures, and policies can be determined, predicted, and specified. Business activities engendered by implementing business rules can be used to design the activities of business processes.

However, emergent organization differs from organization that can be so specified. By definition, emergent organization cannot be determined, predicted, and specified. The term 'emergent organization' is used to describe three related process architecture design problems: emergent organization, business change and associated change management, and emergent business processes (non-standardizable processes).

Emergent organization posses a problem for process architecture design. Emergence is a characteristic of organization affecting routines, structure, and process information needs. Feldman's (2000) study of organizational routines shows how even routines are a source of continuous emergent change. A later study shows organizational structures to be emergent, affecting organizational resources planning (Feldman 2004). In organizational knowledge management research, emergence effects organizational knowledge processes (Clarke and Patel 1995; Truex D P, Baskerville R et al. 1999). Markus et al. (2002) identify organization design knowledge processes as emergent having implications for designing supporting IT systems.

Frameworks and theories are proposed to explain the effect of emergent organization on IS development (Clarke and Patel 1995; Truex D P, Baskerville R et al. 1999; Markus M L, Majchrzak A et al. 2002; Warboys B, Snowdon B et al. 2005). Patel (2006) makes emergence a central postulate for designing artefacts that are connected to human (organised) action. 'Emergence is an unpredictable affect of the interrelatedness of multifarious purposes and the means to achieve them that is characteristic of social action. By implication, emergence is the nonspecifiable constraint on rational design because it cannot be determined as design objects, it is off-design.' (Patel, 2006:12). Emergence is sudden and unexpected change indicative of complexity in social systems. It requires process architecture responses in context.

Allied to emergent organization is the second problem of how expected or planned business change can be factored into process architecture design. Research in this area focuses on strategic organizational change. Such change management differs from emergence because change management is amenable to planning and can be predicted. Among those who have proposed change management models are Gordon et. al's (2000) integrated model of change forces focusing on strategic change and Boddy et al.'s (2000) model of supply chain partnering. The third problem of EBP (non-standardisable processes) is discussed in the next section.

\section{BUSINESS PROCESS}

Business processes are of two types standardisable and non-standardisable. The attributes of standardisable processes can be known in advance making the input-process-output relationship invariant and more amenable to design. A business process has specific inputs that are converted into predetermined outputs by a series of value-added tasks for the benefit of customers and resulting in a revenue stream for the business. Such a definition of business process assumes that inputs and outputs are invariant, implying also that the process by which the inputs are converted into outputs is invariant too. Standardisable business processes contain predictable routines and structure. A production process would have certain plant and equipment, human resources, energy and material inputs that are converted into products/services and revenue. Invariant process can be well-defined processes with high volumes, low variation in order and delivery, and short lead-times, where complexity is less and experiential learning is useful.

In contrast, attributes of non-standardisable processes (emergent business processes) only become cognizant in context, making the input-process-output relationship variant and less amenable to specification and predetermined design. Non-standardisable business processes are non-routine and contain many emergent properties that cannot be known in advance. Project management business processes and jobbing process are examples of non-standardisable business processes. Routines and 
structure are not possible to determine for non-standardisable processes. Non-standardisable processes are highly affected by emergence. As evidenced above, emergence affects even organizational routines and structure.

Research into manufacturing processes shows the uniqueness quality of non-standardisable business processes. Hayes and Wheelwright's (1979) product-process matrix is a tool for analyzing the strategic relationship between the product life cycle and the technological life cycle. It characterises the production process as evolving and staged, moving from highly flexible, high-cost process towards increasing standardization. The stages themselves are characteristic of different process structures found in other business activity such as projects, jobbing, and one-off processes. These are nonstandardisable processes whose input-process-outputs vary. Such processes are evident in organizational work involving innovation, knowledge management, project management and other knowledge-intensive business processes. Marjanovic (2005) concludes that knowledge-intensive processes cannot be 'fully pre-defined' and, for this reason, 'automation of this process is neither desirable nor possible.' Here we argue that it is possible to apply IT to non-standardisable or emergent processes.

Theoretically, the key to information management is process architecture design. Data and information is the reciprocal of business process and organisational structure. Ould (2003) classifies process into: core processes, management processes, and support processes. As a support process, sales order process generates data and information on customers, products, delivery and other support activities. Such processes are data intensive. As a management process, process management is highly information-intensive supporting management decision-making. IT is central to process architecture design because it can capture process data and process it to deliver process information for management. IT enables processes and is the bas is for designing process management systems.

The term emergent business process (EBP) describes non-standardisable processes that are dynamic, evolving, knowledge-intensive business processes (Marjanovic O 2005). Markus et al. (2002), define EBP as:

- $\quad$ an emergent process of 'deliberations' with no best structure or sequence;

- $\quad$ highly unpredictable potential users and work contexts; and

- information requirements that include general, specific and tacit knowledge distributed across experts and non-experts.

Markus et al (2002) cite strategic business planning, new product development, and organisation design as examples of EBP. To design process architecture for emergent organization, there are four significant aspects of EBP to be considered:

\section{Predictable business change}

Process architecture should be designed for ease of change to facilitate predictable or planned business change. Such business change can be predicted and planned, and it requires process flexibility. Shaw et al. (2007) define flexibity as 'the ability to change organizational capabilities repeatably, economically and in a timely way.' (p.92) Predictable business change occurs because organizations want to improve their performance, efficiency and effectiveness to counter competition and to respond to market change. The elements of the change programme are known. Current process management, modelling, and design techniques assume predictability.

\section{Emergence}

Emergence differs from predictable business change or planned change because it is unpredictable and sudden. Process and information requirements emerge. Emergent process has no best structure or sequence. It is not specifiable for the purpose of deliberate design. However, EBP do coexist with standardisable processes.

\section{Process actors}

Emergence suggests a greater role for organizational actors involved in process enactment. Ould (2003) calls them 'process actors'. They are the process owners who are responsible for the performance and continuous improvement of processes. They are prerequisite of process design and Ould proposes that they should be enabled to design processes. Process actors capable of designing are necessary for EBP, which is a key concept of the Theory of Deferred Action discussed in the next section. 


\section{Reciprocity}

Organizational process design and IT systems design should be consistent. Snowdon and Kawalek (2003) observe that the design of IT systems affects organization and the design of organization affects IT systems. There is a reciprocal relation between them. The emergence that affects organization also has an impact on the supporting process architecture.

These four issues are integral to process architecture design. What is an appropriate conceptual basis for process architecture design in this context? How should process support IT systems be conceptualised? A potential action and design theory capable of addressing these issues is outlined next. It forms the basis for the proposed theoretical model.

\section{THE THEORY OF DEFERRED ACTION}

Gregor (2006) elaborates the nature of theory in information systems by demarcating five interrelated types: (1) theory for analysing, (2) theory for explaining, (3) theory for predicting, (4) theory for predicting and explaining, and (5) theory for action and design. The theoretical model presented in the next section draws on the Theory of Deferred Action, which is a 'theory for action and design'. It is a 'process theory' in terms of Sol's (1995) classification discussed in the introduction.

Rather than explain a phenomenon, action and design theories seek to develop 'usable knowledge' that can be applied to design. Walls et al. (1992) propose the IS design theory; Bell (1993) proposes a database design theory from the perspective of organization; Markus et al. (2002) propose a theory to design IT systems to support the work of organizational design; and Arnott (2006), one for the design of decision support systems. These theories aim to inform the design of IT artifacts. Shaw et al., (2007) propose the business process management system pyramid architecture to design process architecture that evolves with business change.

The Theory of Deferred Action proposes three design dimensions: planned action, emergence, and deferred action. The correlation of the planned action and emergence dimensions determines types of organization and systems design possible, as illustrated in Figure 1. The planned action dimension is typical of the ontological assumptions made in existing approaches to process architecture design. It assumes that design objects can be predetermined and specified. It results in the specified systems type indicated at point B. Existing process modelling techniques seek such specifiable design objects. Only those design objects not affected by emergence can be specified.

By introducing the emergence design dimension, the specifiability of design objects becomes less. Since the object of design will emerge in the future they cannot be specified. How a particular design will be used in emergent conditions cannot be specified. To cope with this type of design the theory proposes the notion of 'deferred action', the third design dimension. Deferred action assumes that actual action is superior to any formal design in particular contexts and facilitates such action in the designed artefact. Catering for deferred action results in the 'deferred systems' type depicted at point A. Deferred systems are a 'a way of achieving formal objectives that combines knowable rules and procedures with actuality' and they are 'inherently future-oriented...' (Patel 2006). Mathematically, a deferred system is a continuous system with much randomness. This facilitates design objects that become necessary because of emergence. 
Figure 1: Types of Organization and Systems Design

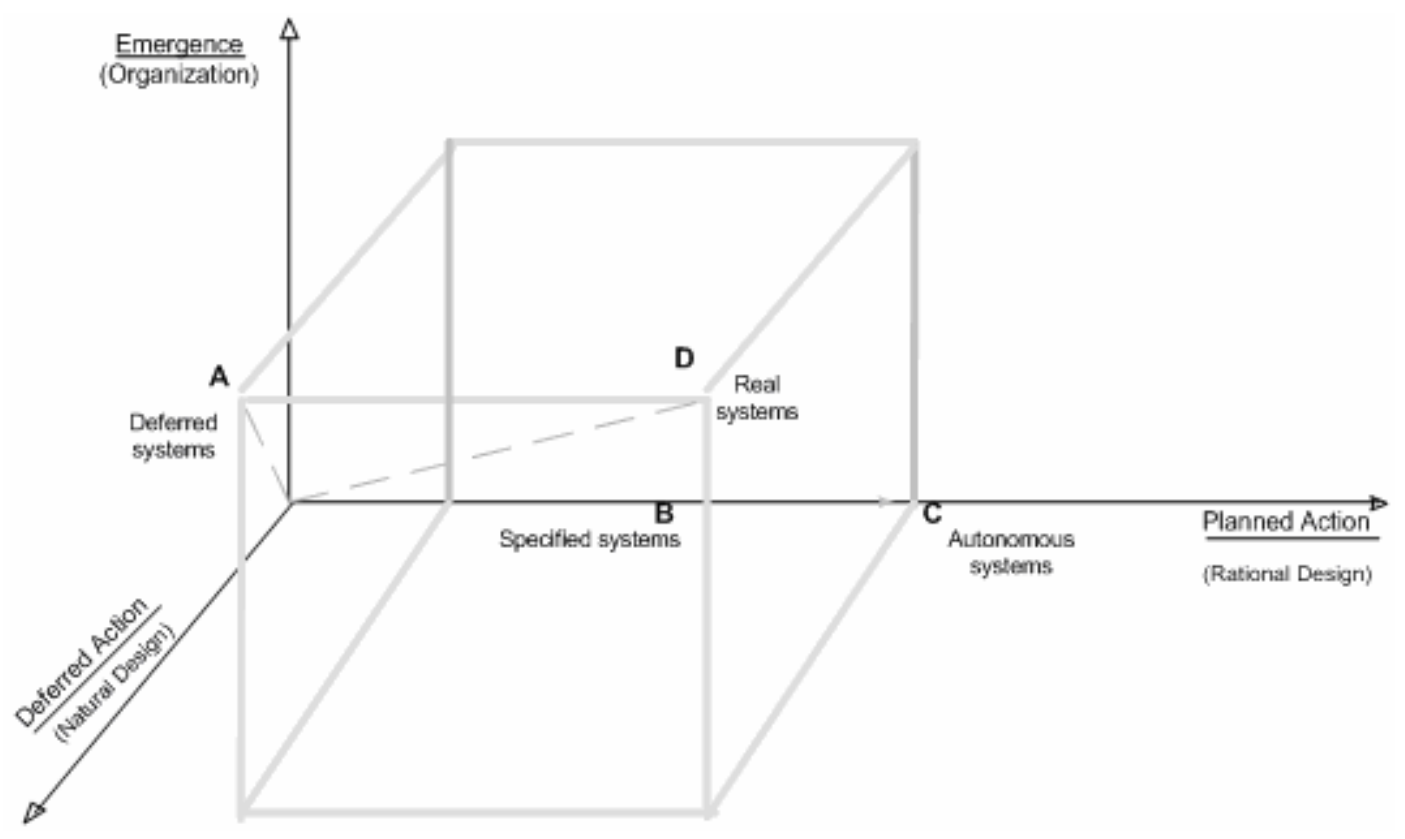

Critically, the theory introduces the deferred action dimension as a synthesised element to design for emergent organization. The deferred action construct accounts for human action and organizational behaviour, or emergent organization, evidenced by the literature earlier. It thus synthesises planned action and deferred action necessary because of emergent organization. The deferred systems type is consequently a synthesis of planned action and action necessary because of emergent organization, deferred action. This is emergent action that cannot be predetermined as design objects.

The theory renders process architecture design for EBP, and emergent organization generally. This is done as the deferred systems type. EBP can be designed as deferred systems. Elliman and Eatock (2005) have applied the 'deferred design decisions' design principle, stemming from the theory, to develop IT systems to support non-standard legal arbitration processes. Sotiropoulou and Theotokis (2005) have applied the theory to develop egovernment systems using service-oriented process architecture (service-oriented architecture is cited later as an example of the proposed theoretical model). The theory has been applied to develop tailorable information systems (Theotokis, Gyftodimes et al. 1996; Stamoulis D, Kanellis P et al. 2001) and e-learning systems (Dron, Boyne et al. 2003), where learning itself is characterised as a deferred system because of the temporal and cognitive distance required for learning to happen. These applications of the theory in diverse fields establish its generality.

\section{CYBERNETICS AND ACTIVE MODELS}

Formal design needs to cater for variant behaviour required in actual organizational situations. The deferred action construct enables such variant behaviour in formal design. Modelling this type of organizational behaviour is discussed in this section. Deferred action can be operationalised with the cybernetic concept of 'non-trivial machine' and the 'active model' modelling type. Emergence requires designed process architecture to cater for variance, conceptualised as the non-trivial machine, and maintain a link with ongoing organisation, conceptualised as an active model.

Since deferred action cannot be predicted because of emergence, it is necessary to design systems whose input-process-output structure is variant. Foerster (2003) defines a 'non-trivial machine' as having a variant input-process-output structure. Such a system is unpredictable - the quality we seek for EBP design and emergent organization design generally, because its outputs would vary even if the inputs remain the same. The key is processes taking shape in particular situations. The non-trivial machine concept characterises well non-standardisable process whose complexity is greater - involving functional groups, strategic business units and even different companies. Such processes can be one-off and/or take long time to complete, for example in aerospace, capital goods, pharmaceutical and industrial engineering.

Modelling process architecture as an 'active model' links it well actual organization. The relevance of active models is more general. Groth (1999) conceptualises organization as active model. 
An active model maintains a synchronized link with the subject that it models (Snowdon B and Kawalek P 2003), in this case business processes. Warboys et al., (2000) used active models to develop process-oriented IT support systems. However, active models do not realise the non-trivial machine because the input-process-output is invariant in active models. But active models are important in the proposed theoretical model because they maintain a synchronization link with the subject - in this case EBP.

How should the design/designer be conceptualised in the context of emergence? With a variant input-process-output, the question of who designs it arises. Since emergence precludes complete predetermined designed, process actors should be enabled to design EBP. Additionally, both the nontrivial machine and active models imply an active role for process actors in designing systems. In this context, process actors are termed 'active designers'.

This has theoretical implications for process modelling techniques. There are few theoretical views on business process modelling. Melão and Pidd (2000) note a conceptual framework for process modelling, the role activity diagram approach. Melão and Pidd's own conceptual framework is a taxonomy of extant approaches to process modelling. They classify the approaches into: deterministic machines, complex dynamic systems, interacting feedback loops, and social constructs. None of this theoretical work however addresses emergent organization and EBP as characterized in this paper. The modelling techniques intrinsically result in static models, as opposed to active models type required for emergent organization. The implications of emergence for processes modelling are considered after next presenting the theoretical model for process architecture design.

\section{THEORETICAL MODEL OF PROCESS ARCHITECTURE DESIGN FOR EMERGENT ORGANIZATION}

Shaw et al. (2007) define a model as a 'planned abstraction of reality represented in a form that is usable by a human.' (p.95). A theoretical model for designing is a planned abstraction based on some theory. Here the theoretical model is based on the Theory of Deferred Action. Its purpose is to support humans' design activity.

Akin to design models, a theoretical model can perform three functions: it can be explanatory, it can contain reasoning facility, and it can be basis for designing. An example of a theoretical model that explains a phenomenon is Currie and Parikh's (2006) integrative model of value creation from web services. Theoretical mathematical models are most powerful for reasoning. No reasoning models exist for process architecture design. Snowdon and Kawalek's (2003) active meta-process model is a conceptual model for designing process architecture. The theoretical model developed in this paper is for designing. It is an 'action and design' theoretical model, rather than simply an explanatory model, but does not contain reasoning power. It draws on and is deduced from the Theory of Deferred Action, the non-trivial machine concept, and active models discussed above.

The theoretical model is for improving EBP design but it can be used for standardisable business process design too, as standardisable processes are affected by emergence in the long run. It is capable of addressing predictable business change and unpredictable EBP requirements. Change management is relatively non-problematical because the associated process architecture can be predicted and specified. EBP cannot be similarly specified because they emerge in unpredictable and sudden ways. The unpredictable class of business processes cannot be pre-defined and pre-specified for design purposes. The cause of this unpredictability is emergent factors. The theoretical model helps improve our understanding of how to design EBP by understanding the effect of emergence on the design of systems in general.

\section{THEORETICAL CONSTRUCTS}

Designing for emergent organization is problematical and complex. The design has to cope with endogenous and exogenous business factors, some predictable and others emergent. There are prominent established research streams relevant for understanding these factors, which also form the basis for proposing the theoretical model. The theoretical model contains five constructs, shown in Table 1, drawn from the information systems development (specified design), organization studies (emergent organization), deferred action, deferred design, and ebusiness model research streams. 
Table 1: Construct Definition

\begin{tabular}{|l|l|l|}
\hline Construct & Definition & Evidence Base \\
\hline Specified design & $\begin{array}{l}\text { Design that requires complete specification of } \\
\text { requirements. Specification is central to designing } \\
\text { process architecture or 'infrastructure software' and } \\
\text { information systems. Design is a rational process. }\end{array}$ & $\begin{array}{l}\text { (NATO 1968; } \\
\text { Demarco 1978; } \\
\text { Mumford, Hirschheim } \\
\text { et al. 1985) }\end{array}$ \\
\hline Emergence & $\begin{array}{l}\text { Sudden and unpredictable occurrence of events that make } \\
\text { rational design by specification alone impossible. }\end{array}$ & $\begin{array}{l}\text { (Feldman, 2000; } \\
\text { Feldman, 2004; Patel } \\
\text { 2006) }\end{array}$ \\
\hline Deferred action & $\begin{array}{l}\text { Consequence of relating specified design with emergent } \\
\text { organization is deferred action. Design that cannot be } \\
\text { predicted because of emergence is deferred to } \\
\text { organizational actors or 'process actors.' }\end{array}$ & $\begin{array}{l}\text { (Elliman T and Eatock } \\
\text { J 2005; Patel 2006) }\end{array}$ \\
\hline Deferred design & $\begin{array}{l}\text { Deferred design is design by 'action designers' } \\
\text { (organizational actors) within formal design to cope with } \\
\text { unknowable emergence or 'equivocal reality'. }\end{array}$ & $\begin{array}{l}\text { (Purao S, Truex D et al. } \\
\text { 2003; Dron J 2005; } \\
\text { Elliman T and Eatock J } \\
\text { 2005; Patel 2006) }\end{array}$ \\
\hline $\begin{array}{l}\text { Process } \\
\text { architecture }\end{array}$ & $\begin{array}{l}\text { Process architecture is composed of artifacts that are a } \\
\text { combination of business process design and supporting } \\
\text { IT systems design. The process architecture is a socio- } \\
\text { technical system. }\end{array}$ & $\begin{array}{l}\text { (Beeson I, Green S et } \\
\text { al. 2002) Marjanovic O } \\
\text { 2005; Snowdon B, } \\
\text { Warboys B et al. 2006) }\end{array}$ \\
\hline ebusiness model & $\begin{array}{l}\text { eBusiness model is composed of business processes and } \\
\text { supporting IT systems designed to generate and sustain } \\
\text { revenue streams. It is based on the concept of 'business } \\
\text { model' for producing, delivering and selling product or } \\
\text { services of value to customers and capable of creating } \\
\text { wealth. }\end{array}$ & \begin{tabular}{l} 
Margretta J 2002) \\
\hline
\end{tabular} \\
\hline
\end{tabular}

\section{Specified design}

The term specified design is used to describe design that requires complete specification of requirements based on construing design as a rational process. Specification is central to rationally designing process architecture or 'infrastructure software' and information systems. Information systems development approaches (Demarco 1978; Yourdon and Constantine 1978; Gane and Sarson 1979) and IS development methodologies (Martin J and Finkelstein C 1981) make specification a prerequisite for designing rationally. The resultant systems models are static as they contain no link with the subject domain modelled.

Dearden (1972) commented early on the limitations of rational or specified design. He stated that it is impossible to pre-design all the information requirements for a company. Attempts to cope with business change within this paradigm result in system evolution (Snowdon B, Warboys B et al. 2006) as a software engineering solution to business change. Business change has engendered proposals for dynamic modelling (Giaglis 1999) and suggestion for 'postmodern software development' (Robinson, Hall et al. 1998). Swartout and Balzer (1982) sought to break form the rational design paradigm by proposing that 'requirements' and 'implementation' are not discrete but 'intertwined.'

\section{Emergent organization}

Emergence is the efficient cause of the difficulties with specified design. Specifically, for information systems design, Truex et al. (1999) propose the explicit recognition of emergence in IS development approaches. Baskerville et al., (1992) are more radical in proposing 'amethodological' approaches, in which phased development or rational design is underplayed for a continuous development approach akin to deferred systems.

Wieck (2004), the organization theorist, argues for design by 'underspecification' as a solution to business change. The basic idea is to gather a specification that forms the 'skeleton' for the design and enabling organizational actors to fill in the 'flesh' in actual organizational contexts. The proposal is a general solution to the problem of emergent organization too. It is key to the proposed theoretical model, as it underpins the deferred action, deferred design, and process architecture constructs of the model.

Process architecture design has moved away from individual 'applications' to organisationoriented design, centrally recognising organizational change and complexity. McDermid (1994) calls approaches to requirements engineering that focus solely on applications functionality 'orthodox'. He 
calls for an organizational focus to address requirements comprehensively for changing organization. This organizational focus is addressed by process-oriented IT systems development and research funded by UK government agencies (Henderson 2000).

\section{Deferred action}

The consequence of relating specified design with emergent organization is deferred action (Patel 2006). Design that cannot be predicted because of emergent factors is deferred to organizational actors or 'process actors.' Defe rred action not only explicitly recognises the limitation of specified design by adhering to the notion of underspecification but, critically, provides a way forward to design systems for emergent contexts. Since design by complete specification of requirements is precluded by emergence the design of the 'skeleton', to use Wieck's (2004) term, should include the capability to do deferred design. The notion of tailoring information, based on deferred action, for specific contextual needs was recognised earlier by Macmillan (1997).

\section{Deferred design}

As the design of a complete artefact is not possible, deferred design is necessary. Michl (2002) regards all design as 'redesign', meaning that all design is incomplete. In this paper it is termed deferred design, which recognises the incompleteness of design and enabling continuous design. The need for deferred design is acknowledged by IS and software researchers (Theotokis, Gyftodimos et al. 1997; Truex D P, Baskerville R et al. 1999; (Carey J E and Carlson B A 2000). Deferred design is made possible within a formally designed framework, distinguishing it from instrumentalism.

Design for changing and emerging processes is deferrable as deferred design to process actors in actual contexts. (Dron J 2005; Elliman T and Eatock J 2005; Sotiropoulou A and Theotokis D 2005). Researchers affiliated to the International Federation of Information Processing (IFIP) recognise the importance of deferred design (Purao S, Truex D et al. 2003).

\section{Process architecture}

Process architecture is composed of artifacts that are a combination of business process design and supporting IT systems design. An example is customised XML scripting. The process architecture is thus a socio-technical system (Mumford 2000). The technical system element of the process architecture is also called 'infrastructure software.'

Process architecture may be classified using Keen and Scott-Morton's (1978) classification. They classify decision processes into highly-structured, semi-structured and unstructured, which is useful for business process design. Process architecture that supports emergent business processes is unstructured.

\section{Ebusiness model}

An ebusiness model is a model of the future. It is a model of something that will be realised. Such models are also termed 'to-be models', as opposed to 'as-is models' that model the current system of interest. Weill and Vitale (2001) discuss the transition that firms need to make from business models to e-business models. The centrality of business model is recognized in the literature. To-be business models improve understanding of enterprise success and are designed to produce, deliver and sell products or services that add value for customers and create wealth (Margretta J 2002). An objectified business model improves a company's knowledge of its purpose and operations, resulting in explicit organizational knowledge and explicit business value creation knowledge.

Process architecture design is effective when based on sound business model. Business models and e-business models explain how a business organization should organise its activities to create value for customers. However, the body of literature on e-business models lacks the necessary commensurate conceptualisation of the requisite process architecture design to support processes to achieve goals. Few ebusiness models recognize emergent organization. For instance, Patel (1995) proposed emergent form of IT governance to support global ebusiness models.

The constructs detailed above are related and their interrelationships result in an ebusiness model capable of emergent behaviour. The relationships are defined in Table 2. An ebusiness model is an expression of these constructs and their interrelationships. Emergence is the independent variable that effects specified design, process architecture and ebusiness model. Specified design and deferred design co-exist in the process architecture design. Deferred action is necessary when specified design is correlated with emergent organization. 
Table 2: Defining construct relationships

\begin{tabular}{|l|l|}
\hline Construct & Relationships \\
\hline Specified design & $\begin{array}{l}\text { Specified design is the basis for designing an ebusiness model whose process } \\
\text { architecture is emergent. }\end{array}$ \\
\hline Emergence & $\begin{array}{l}\text { Emergence is the independent variable that effects specified design, process } \\
\text { architecture and ebusiness model. }\end{array}$ \\
\hline Deferred action & $\begin{array}{l}\text { Deferred action is the consequence of relating specified design to emergence. } \\
\text { Deferred action is necessary in emergent organization. }\end{array}$ \\
\hline Deferred design & $\begin{array}{l}\text { Catering for emergent organization is enabled by deferred design and the } \\
\text { deferred design decisions principle. }\end{array}$ \\
\hline Process architecture & $\begin{array}{l}\text { Process architecture is the enabling mechanism for emergent organization } \\
\text { and its consequence. }\end{array}$ \\
\hline ebusiness model & $\begin{array}{l}\text { ebusiness model is an expression of the constructs and their } \\
\text { interrelationships. It is designed by specified design and contains deferred } \\
\text { design capability in order to respond to emergence. The process architecture } \\
\text { is emergent. }\end{array}$ \\
\hline
\end{tabular}

The model has generic applicability. Company resources and structures are organised as business processes. Since no competitive business is free of business change, the theoretical model has generic applicability to manufacturing and service sectors. Growth and innovation are important for all businesses, and they are affected by markets and competitors' actions. Central for achieving growth and generating innovation is the design of ebusiness models and business process. Innovation in particular is subject to emergence.

The central element affected by business change and emergence is business process. The ability of businesses to meet business change and emergence depends on appropriate process architecture being in place. Both growth and innovation can be facilitated on agile process architecture.

\section{RELIABILITY, VALIDITY AND PROPOSITIONS}

The theoretical model is checked in this section for reliability and validity. Reliability and validity are of interest to improve the strength of the knowledge claim. Reliability is concerned with repeatability and corroboration. Validity is concerned with the appropriateness or meaningfulness of the knowledge claim (Rosenthal R and Rosnow R L 2008). The theoretical model can be assessed for reliability and validity by checking its internal and external consistency. Internal consistency is discussed in this section and external consistency in the next section.

The internal consistency of the theoretical model depends on the veracity of the Theory of Deferred Action on which it is based. The theory is a 'far-reaching' theory (Kaplan A 1964), as it addresses the design of socio-technical systems (Mumford and Beekman 1994; Mumford 2000). The veracity of the theory is attested to by its application. Researchers have drawn on its deferred design decisions principle (Patel, 2005) to design IT systems capable of coping with organizational change and emergence (Fitzgerald, 1999; Elliman T, 2005). It is the subject of joint research proposal with the UK Ministry of Defences' Defence Science and Technology Laboratory (dstl). The theory's construct of deferred system is proposed to be realised as an IT system using technology developed by the Informatics Process Group at Manchester University’s Computer Science Department.

Is it possible to design an enterprise architecture that is able to cope with both predictable outcomes and unpredictable outcomes? This depends on the veracity of the propositions deduced from the theoretical model that inform process architecture design. The explanatory capability of the theoretical model is deepened because it combines relevant constructs from cybernetics and modelling. Consequently, the value of business propositions derived from the model is improved. Research propositions are useful because they direct further research and clarify the logic of the theoretical argument. As propositions involve concepts (Whetten D A 1989), the validity and interrelations of the concepts is clarified when stated in propositional form. Propositions 'should be limited to specifying the logically deduced implications for researchers of a theoretical argument.' (Whetten D A 1989) p.492. 
Three propositions are derived from the theoretical model:

Proposition 1. Process architecture design is effective when based on a sound e-business mo del.

Proposition 2. Organizational emergence affects process architecture design.

Proposition 3. The model of EBP (non-standardisable) process evolves.

The three propositions are logically connected. An ebusiness model seeks to deliver business performance based on process efficiency supported by IT systems. However, organizational emergence determines what is required from the process-oriented IT systems. Therefore, as the non-standardisable processes evolve in response to emergence, so does the supporting IT systems. These propositions are illustrated in the exemplar systems discussed next.

\section{Process-oriented IT systems}

Contribution to improving our understanding and capability of explaining the phenomena of interest constitutes the external validity of the theoretical model. The theoretical model can be used to explain process support IT systems design and methodologies. Conceptualisation of IT systems can be improved based on the theoretical model.

There are implications of the theoretical model for models of EBP and business process modelling techniques. How does the theoretical model inform the methods used to design process architecture? What kind of IT systems design is required to support non-standard business processes and business processes requiring change? A key question is how the theoretical model can contribute to process architecture design problem-solving. The explanatory capability of the theoretical model can be demonstrated by considering exemplar systems. The kinds of design problems it has to be capable of addressing include emergent organization, business change, and competitors' moves. In this section, the theoretical model is exemplified.

Models inform process-centered IT systems design. In turn, planning and problem-solving with models require clear design and development methodology. Shaw (2007) defines a model as: 'A model is a planned abstraction of reality represented in a form that is usable by a human.' (p.95). Slack (Slack $\mathrm{N}$ and Lewis M 2005) proposes a model of business process technology. Larger and Horte (T Larger and Horte 2005) have developed a classification system for process technology. The two exemplar systems discussed in this section are similarly model-based systems.

Process-oriented approach to IT systems development is adopted in the research literature. This research is at the enterprise level. The UK Government's grant-awarding research body Engineering and Physical Sciences Research Council (EPSRC) supported research into enterprise process-oriented systems architecture. It focused on how organizational change affects the development of IT systems. The result of this research is process-oriented systems architecture as reported in Henderson (2000).

In terms of cybernetics, process-oriented approach can be categorized as trivial machine and nontrivial machine, explained above. Much research can be categorised as trivial machine conceptualization of process-oriented IT systems, as reported in Ould (2003) and (Henderson, 2000). Larger and Horte (2005) provide a classification of success factors for developing process technology. Alongside this research is research that can be categorized as non-trivial machine conceptualisation of process-oriented IT systems. A particular strand of interest is on active models (Warboys B, Greenwood R M et al. 2000). Active models address the problematical issue of change in business processes and the necessary commensurate change in IT systems.

\section{Exemplar 1 process ProcessWeb}

The ProcessWeb is an IT system developed by the Informatics Process Group at the Computer Science Department of Manchester University, UK. ProcessWeb adopts a process-oriented perspective to conceptualise and design systems architecture suitable for evolution, which is necessary to cope with organizational change (and emergence). Theoretically, ProcessWeb adopts a systems approach, particularly Viable Systems Model (Beer 1979) and active model perspective on business process (Greenwood R M, Robertson I et al. 1995; Warboys B 1995; Snowdon B and Kawalek P 2003; Warboys B, Snowdon B et al. 2005).

The active model provides the synchronisation link between business process change and supporting IT systems. This achieved by maintaining a synchronisation link, through the coordination layer, with the subject of the system - in this case business processes. In active models the metaprocess is the process of changing a process (Warboys B, Greenwood R M et al. 2000). An active 
model is contrasted with a 'passive model' which is static rather than dynamic, representing the position at the point of observation and lacking an updating mechanism (Beeson I, Green S et al. 2002). Integral to the active model of business process is the process 'coordination layer'.(Warboys B, 2000). The coordination layer enables the co-evolution of business process and IT systems.

In terms of cybernetics, ProcessWeb can be categorised as a non-trivial machine conceptualization of business processes with one critical qualification. In ProcessWeb, the input-process-output relationship is non-variant, whereas in non-trivial machines it is variant. Whilst the active model provides a link with the actual business processes modelled, the system architecture of ProcessWeb does not enable variable input-process-output.

ProcessWeb illustrates four of the five constructs, and their interrelationships, of the deferred action theoretical model. The theoretical model directs modelling attention to emergent factors. In ProcessWeb, specified design is based on the active model. As the active model keeps a synchronised link with the business domain, it accounts for emergent factors. There is no direct enablement of deferred action. However, the synchronisation link in the active model is the mechanism that enables organizational actors to keep the IT system relevant to business needs. It indirectly caters for deferred action. The conceptual model of the ProcessWeb is based on business process and so its system architecture is process-oriented. As ProcessWeb is an experimental system it has no e-business model.

The three propositions deduced from the theoretical model are accounted for in ProcessWeb. Concerning proposition 1, ProcessWeb is capable of supporting any process-based business model since its architecture is proces s-oriented. It seeks to be effective by catering for business processes. Proposition 2 is met because organizational change, an aspect of organizational emergence, is catered for by the synchronisation link in the active model. Since ProcessWeb is predicated on software evolution, it meets Proposition 3 of non-standardisable processes evolving with the same magnitude of IT systems evolution.

\section{Exemplar 2 service oriented architecture (SOA)}

The underlying design principle of Service Oriented Architecture (SOA) is the provision of software services to business on demand. The services are loosely coupled or configured to meet specific business process needs (Jones S 2005). IT system architecture, including computer networks, is accessed without constraints to deliver required services.

SOA illustrates five of the constructs and their interrelationships of the deferred action theoretical model. Specified design is based on software (and hardware) components. A software component is a system element offering a predefined service and able to communicate with other components. Since software components are 'non-context-specific', they enable emergence through composition to be represented in IT systems. Software componentry, indirectly, makes deferred action at the level of systems designers possible (as opposed to organizational actors). Concerning the process architecture, as components are non-context-specific, they can be mapped onto existing or newly designed business processes. The technical system architecture is dis tributed computing based on application servers. SOA, within which software componentry is embedded, is suited to support emergent e-business models. Business processes and the needs of organizational actors underpin SOA. It recognises the interconnectedness of organization, data and applications. The architecture is designed to deliver computational resources on demand as required by business users, thereby serving any ebusiness model.

The three propositions deduced from the theoretical model are accounted for in SOA. Concerning proposition 1, since the concept of service underpins SOA, any underlying e-business model is supported. IT systems are configured to support specific, and unique, business processes. Proposition 2 is met because organizational change (and emergence) is catered for by re-configuring services. Similarly, Proposition 3 is met as non-standardisable processes are directly catered by re-configuring services as required.

Generally, the exemplar systems are indicative of a trend towards a new conceptualization of IT systems. In terms of cybernetics, the emerging conceptualisation is tending towards IT systems as nontrivial machines whose input-process-output structure is variant. This conceptualisation mirrors the deferred action theoretical model developed above and the derived propositions. It is evident in systems like ProcessWeb and emerging technologies like software componentry, SOA, and the Semantic Web.

The theoretical model has wider implications for process management. Process management involves approaches to process improvement. It encompasses interest in business process modelling languages and theory of process management change. Process management encompasses methodologies, techniques and tools to support the re(design) of business processes. Business process design is informed by business process modelling languages. Practitioners particularly are interested in modelling languages. Kettinger et al (1997) surveyed 25 methodologies, 72 techniques and 102 tools. 
In terms of the theoretical model, the current class of modelling languages focus only on explicit knowledge of the organization and the things that can be specified.

Of the four perspectives on business processes elaborated by Melão and Pidd (2000), business processes as interacting feedback loops and business process as social contracts reveal that the possibility of the exact specification of business processes is limited. Business processes as deterministic machines and business process as complex dynamic systems, the other two perspectives, require exact specification of processes. But the perspective and modelling languages used to model processes from these perspectives assume objectivity and fixed ontology. Objectivity is not assumed in the social contract perspective. In terms of cybernetics, they all assume the possibility of business processes as trivial machine. Given emergence, it is necessary to acknowledge emergent ontology. For instance, when business partnerships form a new business vocabulary and artifacts are also likely.

\section{MANAGERIAL IMPLICATIONS}

The theoretical model has implications for business managers and IT managers. Managers need to reconsider the extent to which IT architecture (process architecture) and methods for developing it can be specified. The distinction between a definitive and static business and similar IT architecture becomes blurred in emergent organization. Companies procuring IT solutions from vendors who supply fixed architecture need to reconsider their IT strategy.

Management have to think about IT centrally in emergent organization. IT cannot simply be supporting function. Managers have to revise their concept of managing in an emergent organization. Since fixed ontology becomes inappropriate in emergent contexts, management constructs need to be revised to cope with emergence.

Management have to think of ebusiness models as composing two elements, the specified element and the deferred element. The specified element should be based on sound determinable business strategy and objectives. The deferred element should operate within the boundaries of the specified element. However, it is conceivable for the ebusiness model to change marginally or radically to generate new revenue streams. Existing on-line businesses have added new revenue streams by providing services or selling products that were not in the original business model. The ebusiness model needs to be specified such that its evolution is deferred.

The implication of emergence for enterprise resource planning is that such planning activities have to be redefined as continuous. Manager's ideas of plans per se need to be changed. Rather than a discrete event planning needs to be continuous activity. Resource allocations and work design would change to meet emerging market conditions and competitors actions. There is also an implication for integrated systems. Such change would also affect cost accounting, which needs to be reported to provide integrated strategic knowledge.

\section{CONCLUSION}

The flexibility of process architecture is important for emergent organization. A theoretical model based on the Theory of Deferred Action was elaborated. The purpose of the model is to understand better how organizational change and emergence can be catered for in IT systems supporting business processes. The model's five constructs were detailed and their interrelationships explained. Three propositions were derived from the model. The theoretical model and the propositions were exemplified in two IT systems.

The proposed model has implications for models of business processes, particularly nonstandardisable or emergent business processes. It also has implications for business process modelling methodologies and techniques. The latter in turn has implications for practice, which are beyond the scope of this paper's consideration but nonetheless important.

The theoretical model has business implications that require further research. The model's deficiencies include consideration of market leadership, strategic differentiation, and revenue generation, as a minimum basis for designing business processes and process architecture. Further empirical research, particularly cases studies of IT systems purporting to cater for organizational change and emergence, are needed. The Theory of Deferred Action is the subject of proposed research collaboration with the UK government's Defence Sciences and Technology Laboratory and the Informatics Process Group (IPG) at Manchester University. The IPG collaboration will seek to technologically realise some of the theoretical constructs presented in the theoretical model.

The theoretical model suggests a research agenda directed to improving process architecture flexibility. The paper has applied the Theory of Deferred Action to business process flexibility and 
improved our understanding of the robustness of process architecture and limitations of specificationbased design. The implications of the theoretical analysis with regard to process architecture design require further research. The important issues that have been identified theoretically as promising areas of further research include: scope of process specification, relationship between EBP and deferred action, and development of techniques to model EBP. An important question is raised. What is the right magnitude of deferred action for particular EBP? This question is synergistically related to the impact that emergence has on organizational design. Levels of emergence determine levels of deferred action required. This relationship is a central focus of further deep research at the Brunel Organization and Systems Design Center [ BOSdc ].

In particular, further research will focus on the problem of demarcating specifiable and deferrable business objects in ebusiness systems design. This requires clear definition of specification and deferment in terms of the business services enabled by IT systems. Understanding ebusiness modelling and ebusiness systems designing as an emergent or continuous activity is an allied further research theme. Understanding the dis tinction between specifiable objects and deferrable objects and emergent design can be improved as services science. A service is an interaction between a provider and a client that produces and captures value for the client. Developments in Service Oriented Architecture and web services are important but they are predicated on specified design. We seek to understand the scope of deferrable design within service science.

\section{REFERENCES}

Arnott, D. (2006). Cognitive Biases and Decision Support Systems Development: A Design Science Approach. Information Systems Journal 16: 55-78.

Baskerville, R, J. Travis, Treux, D. (1992). Systems Without Method. From Proceedings: IFIP Transactions on The Impact of Computer Supported Technologies on Information System Development. 241-270.

Beer, S. (1979). The Heart of Enterprise. New York:John Wiley \& Sons Ltd.

Beeson, I. Green S, Sa, J. (2002). Linking Business Process and Information Systems Provision in a Dynamic Environment. Information Systems Frontiers 4 (3): 317-329.

Bell, D. A. (1993). From Data properties to Evidence. IEEE Transactions on Software Engineering 5 (6): 965-969.

Boddy, D. Macbeth, D. Wagner, B. (2000) Implementing Collaboration between Organizations: An Empirical Study of Supply Chain Partnering. Journal of Management Studies 37 (7): 1003-1017 Nov 2000.

Carey, J. E. and Carlson, B. A. (2000). Deferring Design Decisions in an Application Framework. ACM Computing Survey 32 (1).

Clarke, S. and Patel, N. V. (1995). Structure and Culture of Higher Education in Institutions - Its Impact on Information Systems Strategic Planning. Proceedings from: The Fourth International Conference of the United Kingdom Systems Society on Critical Issues in Systems Theory and Practice. Plenum, London.

Currie, W. L. and Parikh, M. A. (2006). Value Creation in Web Services: An Integrative Model. Strategic Information Systems 15: 153-174.

Dearden, J. (1972). MIS is a Mirage. Harvard Business Review 50 (90-99).

Demarco, T. (1978). Structured Analysis and System Specification. New York: Yourdon.

Dron, J. (2005). Epimethean Information Systemsd: Harnessing the Power of Collective in e-Learning. International Journal of Information Technology Management. 4 (4): 392-404. 
Dron, J. Boyne, C. Mitchell, R. (2003). Evolving Learning in the Stuff Swamp. In Patel N. V. (Ed.) Adaptive Evolutionary Information Systems. 211-228. London: Idea Group Publishing.

Elizinga, D. Horak, T. Chung-Yee, L Bruner, C. (1995). Business Process Management: Survey and Methodology. IEEE Transactions on Engineering Management 42: 119-128.

Elliman, T. and Eatock, J. (2005). Online Support for Arbitration: Designing Software for a Flexible Business Process. Int. J. of Information Technology and Management 4 (4): 443-460.

Feldman, M. S. (2000). Organizational Routines as a Source of Continuous Change. Organization Science 11(6): 611-629.

Feldman, M. S. (2004). Resources in Emerging Structures and Processes of Change. Organization Science 15(3): 295-309.

Fitzgerald, G., Philippides, A. (1999). "Information Systems Development, Maintenance and Enhancement:Findings from a UK Study." International Journal of Information Management 19: 319-328.

Foerster, H. V. (2003). Understanding Understanding. New York: Springer-Verlag.

Gane, C. and Sarson, T. (1979). Structured Systems Analysis: Tools and Techniques. New York: Prentice-Hall.

Georgakopoulos, D. Hornick M. Sheth, (1995). An Overview of Workflow Management: From Process Modelling to Workflow Automation Infrastructure. Distributed and Parallel Databases 3: 119153.

Giaglis, G. M. (1999). Dynamic Process Modelling for Business Engineering and Information Systems Evaluation. Department of Information Systems and Computing. London, Brunel University.

Gordon, S. S. Stewart, W. H. and Sweo, R. (2000) Convergence versus Strategic Reorientation: The Antecedents of Fast-Paced Organizational Change. Journal of Management 26 (5). 911-945.

Greenwood, R. M., Robertson, I. Snowdon R. A., Warboys, B. (1995). Active Models in Business. Processing from: The annual conference on business information technology.

Gregor, S. (2006). The Nature of Theory in Information Systems. MIS Quarterly 30(3): 611-642.

Groth, L. (1999). Future Organisation Design. Chichester:Wiley.

Hayes, R. H. and Wheelwright, S. C. (1979). Link Manufacturing Process and Product Life Cycles. Harvard Business Review January.

Henderson, P. (2000). Systems Engineering for Business Process Change. London: Springer.

Jones, S. (2005). Toward an Acceptable Definition of Service. IEEE Software 22(3): 87 - 93.

Jones, S. (2005). Toward an Acceptable Definition of Service. IEEE Software 22 (3): 87-93.

Kaplan, A. (1964). The Conduct of Inquiry: Methodology for Behavioural Science. Scranton PA: Chandler.

Keen, P.G. and Scott-Morton, M.S.S. (1978). Decision Support Systems: An Organizational Perspective. Reading: MA:PAddision-Wesley.

Kettinger, W. and Grover, V. (1995). Toward a Theory of Business Process Change Management. Journal of Management Information Systems 12: 9-30. 
Kilduff, M. (2007). Celebrating Thirty Years of Theory Publishing in AMR: Award-Winning Articles from the First Two Decades Revisited. The Academy of Management Review (AMR) 32 (2): 332 333.

Larger, T. and Horte, SA. (2005). Success Factors for the Development of Process Technology in Process Industry Part 1: A Classification System for Success Factors and a Rating of Success Factors on a Tactical Level. International Journal of Process Management and Benchmarking. 1(1): 82-103.

Macmillan, H. (1997). Information Systems: Four Good Questions for the Board. In Macmillan, H. and Christopher, M. (eds.) Strategic Issues in the Life Assurance Industry. Oxford: Butterworth Hienemann.

Malao, N. and Pidd, M. (2000). A Conceptual Framework for Understanding Business Processes and Business Process Modelling. Information Systems Journal 10: 105-129.

Margretta, J. (2002). Why Business Models Matter. Harvard Business Review 80(5): 86-93.

Marjanovic, O. (2005). Towards IS Supported Coordination in Emergent Business Processes. Business Process Management Journal 11(5): 476-487.

Markus, M. L. Majchrzak, A. Gasser, L. (2002). A Design Theory for Systems that Support Emergent Knowledge Processes. MIS Quarterly 26: 179-21.

Martin, J. and Finkelstein, C. (1981). Information engineering. Englewood Cliffs, Prentice Hall.

McDermid, J.A. (1994). Requirements Analysis: Orthodoxy, Fundamentalism and Hersey. In Jirotka M and Goguen J. (eds.) Requirements Engineering: Social and Technical Issues. London: Academic Press.

Michl, J. (2002). On Seeing Design as Redesign. Scandinavian Journal of Design History. 12: 7-23.

Miers, D. (1994). Use of Tools and Technology Within a BPR Initiative. In Coulson-Thomas C. (eds.) Business Process Re-Engineering: Myth and Reality. Amsterdam, North-Holland.

Mumford, E. (2000). A Socio-Technical Approach to Systems Design. Requirements Engineering 2 (5): 125-133.

Mumford, E. and Beekman, G. J. (1994). Tools for Change \& Process, A socio-technical approach to business process re-engineering. Netherlands: CSG Publications.

Mumford, R., Hirschheim, R. et al., (eds.) (1985). Research Methods in Information Systems. New York: North Holland.

NATO, S. C. (1968). Conference on Software Engineering, Germische.

Ould, M. A. (2003). Preconditions for Putting Processes Back in the Hands of their Actors. Information and Software Technology. 45: 1071-1074.

Patel, N. V. (1995). Emergent Forms of IT Governance to Support Global E-Business Models. Journal of Information Technology Theory and Application. 4 (2): 1-24.

Patel, N. V. (2005). Sustainable Systems: Strengthening Knowledge Management Systems with Deferred Action. International Journal of Information Technology Management. 4 (4): 344-365.

Patel, N. V. (2006). Organization and Systems Design: Theory of Deferred Action. Basingstoke: Palgrave Macmillan. 
Purao, S. Truex, D. Cao, L. (2003). Now the twain shall meet: Combining social sciences and software engineering to support development of emergent systems. Proceeding from: Ninth Americas Conference on Information Systems, Tempa, Florida.

Reijswoud, V. Mulder, H. Dietz J. (1999). Communicative Action-Based Business Process and Information Systems Modelling with DEMO. Information Systems Journal 9: 117-138.

Robinson, H., Hall, P. Hovenden, F. Rachel J. (1998). Postmodern Software Development. The Computer Journal. 41 (6): 363-375.

Rosenthal, R. and Rosnow, R. L. (2008). Essentials of Behavioural Research. New York: McGrawHill.

Slack, N. and Lewis, M. (2005). Towards a Definitional Model of Business Process Technology. International Journal of Process Management and Benchmarking 1 (1): 3-24.

Snowdon, B. and Kawalek, P. (2003). Active Meta-Process Models: A Conceptual Exposition. Information and Software Technology. 45: 1021-1029.

Snowdon, B. Warboys, B. Greenwood R. M. Holland, C. P. Kawalak, P. Shaw, D. R. (2006). On the Architecture and form of Flexible Process Support. Software Process Improvement and Practice in press.

Soh, C. and Markus, M. L. (1995). How IT Creates Business Value: A Process Theory Synthesis. Proceedings From: $16^{\text {th }}$ : International Conference on Information Systems, Amsterdam.

Sotiropoulou, A. and Theotokis, D. (2005). Tailoring Information Systems: An Approach Based on Services and Service Composition. Int. J. Information Technology and Management. 4 (4): $366-$ 391.

Stamoulis, D. Kanellis, P. Martakos, D. (2001). Tailorable Information Systems: Resolving the Deadlock of Changing User Requirements. Journal of Applied System Studies 2 (2).

Swartout, W. and Balzer, R. (1982). On the Intertwining of Specification and Implementation. Communications of the ACM. 25 (7): 438-440.

Theotokis, D., Gyftodimes, G. Geogiadis, P. Philokyprou, G. (1996). Atoms: A Methodology for Component Object oriented Software Development Applied in the Educational Context. Proceedings from: International Conference on Object Oriented Information Systems, London, UK, Springer.

Timmers, P. (1999). Electronic Commerce. Chichester: Wiley.

Truex, D. P. Baskerville, R. Klein, H. K. (1999). Growing Systems in Emergent Organisations. Communications of the ACM. 42 (8).

Walls, J. G. Widmeyer, G.R. El Sawy, O.A. (1992). Building an information system design theory for Vigilant EIS. Information Systems Journal. 3 (1): 36-59.

Warboys, B. (1995). The software paradigm. ICL Technical Journal 10 (1): 71-79.

Warboys, B. Greenwood, R. M. et al. (2000). Modelling the Co-Evolution of Business Process and IT Systems. In Henderson, P. Systems Engineering for Business Process Change. London, Springer. Warboys, B. Snowdon, B.Greenwood, R. M. Seet, W. Robertson, I Morrison, R. Balasubramaniam, D. Kirby, G. Mickan, K. (2005). An Active-Architecture Approach to COTS Integration. IEEE Software. 20-27. 
Weber, R. (2003). Editor's comments: Still Desperately Seeking the IT artefact. MIS Quarterly. 27(2): iii-xi.

Weick, K. E. (2004). Rethinking Organizational Design. In Boland, R. J. and Callopy, F. (eds.) Managing as designing. Stanford, California: Stanford University Press.

Weill P. and Vitale, M. R. (2001). Place to space: Migrating to eBusiness Models. Harvard Business School Press.

Whetten, D. A. (1989). What Constitutes a Theoretical Contribution? The Academy of Management Review. 14 (4): 490-495.

Yourdon, E. and Constantine, L.L. (1978). Structured Design: Fundamentals of a Discipline of Computer Program and System Design. New York: Yourdon Press.

Shaw, D. R. Holland, C. P. Kawalek, P. Snowdon, B. Warboys, B. Elemenets of a business process management system: theory and practice. Business Process Management Journal. 13 (1): 91-107. 